\title{
Sais fertilizantes e manejo da fertirrigação na produção de tomateiro cultivado em ambiente protegido
}

\author{
Patrícia F. da Silva', Carlos J. G. de S. Lima ${ }^{2}$, Allan C. Barros ${ }^{3}$, \\ Everaldo M. da Silva ${ }^{4} \&$ Sérgio N. Duarte ${ }^{5}$
}

\begin{abstract}
RESUMO
Avaliou-se o efeito da aplicação em excesso de fertilizantes via irrigação em solos com diferentes níveis de salinidade, sobre as variáveis produtivas do tomateiro em ambiente protegido localizado no Departamento de Engenharia de Biossistemas da ESALQ/USP, Piracicaba-SP. O delineamento estatístico foi o em blocos casualizados em esquema fatorial $6 \times 2$ com quatro repetições, em que os fatores consistiram em seis níveis iniciais de salinidade do solo $\left(S_{1}=1,62 ; S_{2}=2,40 ; S_{3}=2,98 ; S_{4}=3,48 ; S_{5}=4,63\right.$ e $\left.S_{6}=5,82 d S m^{-1}\right)$ e em dois manejos da fertirrigação $\left(M_{1}\right.$ - Adubos aplicados em fertirrigação obedecendo à curva de absorção de nutrientes da cultura e $M_{2}$ - Cultivo sem aplicação de fertilizantes via água de irrigação). As variáveis fitomassa fresca de frutos e número de frutos foram afetadas estatisticamente, tanto pelo manejo quanto pela salinidade do solo com reduções de 38,82 e 27,31 \% para o manejo $M_{1}$. A interação entre (salinidade $x$ manejo) e a salinidade isolada influenciou significativamente os componentes estudados, exceto para fitomassa seca do caule e raiz na interação. $O$ manejo $M_{1}$ foi superior em todos os componentes de produção estudados quando comparado ao manejo $\mathrm{M}_{2}$. O limiar para a cultivar foi superior ao encontrado na literatura.
\end{abstract}

Palavras-chave: Lycopersicon esculentum Mill, condutividade elétrica do solo, fertilizantes químicos, solução no solo

\section{Fertilizer salts and fertigation management in tomato cultivation in greenhouse}

\begin{abstract}
The effect of application of fertilizers in excess through irrigation in soils with different levels of salinity was evaluated on variables of tomato production, in a greenhouse located in Department of Biosystems Engineering of ESALQ/USP, in Piracicaba, Brazil. The experimental design was randomized blocks, in a factorial scheme $6 \times 2$ with four replications, the factors consisted in six levels of initial soil salinity $\left(\mathrm{S}_{1}=\right.$ $1.62, \mathrm{~S}_{2}=2.40, \mathrm{~S}_{3}=2.98, \mathrm{~S}_{4}=3.48, \mathrm{~S}_{5}=4.63$ and $\mathrm{S}_{6}=5.82 \mathrm{dS} \mathrm{m}^{-1}$ ) and two fertigation managements $\left(M_{1}\right.$ - Fertilizer applied in fertigation obeying the nutrient absorption curve of crop, and $M_{2}$ - Cultivation without application of fertilizers through irrigation water). The variables fresh biomass of fruit and number of fruits were statistically affected by both factors-types of management and salinity levels with reductions of 38.82 and $27.31 \%$ for the $M_{1}$ management. The interaction between salinity $x$ management and salinity isolated significantly influenced components studied, except dry biomass of stem and root for interaction. The management $M_{1}$ performed better for all yield components studied when compared to $M_{2}$ management. The threshold for the cultivar was higher than that found in the literature.
\end{abstract}

Key words: Lycopersicon esculentum Mill, soil electrical conductivity, chemical fertilizers, soil solution

\footnotetext{
${ }_{1}^{1}$ Mestranda em Engenharia Agrícola, UFCG. Rua Aprígio Veloso, 882, Bodocongó, CEP 58429-140, Campina Grande, PB. Fone: (83) $9972-8432$. E-mail:patrycyafs@yahoo.com.br

2 DEAS/UFPI. Campus da Socopo, CEP 64049-550, Teresina, PI. E-mail: kj.gon@bol.com.br

${ }^{3}$ UFAL, Campus Arapiraca. Av. Manoel Severino Barbosa, S/N, Bom Sucesso, CEP 57309-005, Arapiraca, AL. E-mail: allan.cunha.barros@gmail.com

${ }^{4}$ CCGBEAG/UFPI. Rodovia BR - 135, Planalto Horizonte, CEP 64900-000, Bom Jesus, PI. E-mail: everaldo 99@hotmail.com

${ }^{5}$ ESALQ/USP. Av. Pádua Dias, 11, CEP 13418-900, Piracicaba, SP. E-mail: snduarte@carpa.ciagri.usp.br
} 


\section{INTRODUÇÃO}

A produção de hortaliças é um ramo da economia agrícola que possibilita a geração de empregos, desde a semeadura até a comercialização, dentre as quais se destaca o tomate, fruto típico de clima tropical e de importante valor econômico para o país (Filgueira, 2008).

O tomateiro (Lycopersicum esculentum Mill) por se tratar de uma das principais culturas exploradas em estufa plástica resultando em frutos de excelente qualidade comercial garantindo, assim, um lucro maior, vem-se tornando uma das hortaliças mais significativas cultivadas no Brasil (Luz et al., 2007). Destaca-se por estar entre as dez hortaliças mais importantes do mercado brasileiro uma vez que possui excelente valor nutritivo com altos teores de vitaminas A e C, além de ser rico em licopeno (Carvalho \& Pagliuca, 2007).

De acordo com Ayers \& Westcot (1991) o desempenho do tomateiro é reconhecidamente prejudicado quando vegeta em ambiente salino (solo/substratos) já que o tomate é classificado como moderadamente sensível aos sais reduzindo sua produção quando a condutividade elétrica da solução do solo se encontra acima de $2,5 \mathrm{dS} \mathrm{m}^{-1}$. A tolerância das culturas à salinidade é afetada por diversos fatores como o estágio de desenvolvimento no momento da exposição aos sais, duração da exposição aos sais, condições ambientais, propriedades físicas e químicas do solo e do tipo e intensidade do manejo (Maas, 1990).

Segundo Eloi et al. (2007) a tomaticultura sob ambiente protegido é uma atividade promissora, sobretudo nas regiões Sul e Sudeste do Brasil, nas quais o cultivo se dá mediante o uso frequente da fertirrigação. Entretanto, deve-se atentar para o acúmulo de sais fertilizantes no solo uma vez que nesses ambientes é frequente a aplicação excessiva de adubos em função do manejo inadequado utilizado pelos agricultores ou seja, aplicação de fertilizantes via água de irrigação de maneira excessiva prejudicando, assim, o desenvolvimento da cultura (Bernardo et al., 2006).

O excesso de fertilizantes, o uso de água salina e a ausência de drenagem adequada, são fatores que resultam em condições desfavoráveis ao desenvolvimento das culturas acelerando a degradação do solo (Silva et al., 2008). Em ambiente protegido os problemas de salinização podem, ainda, ser maiores em virtude de não haver lavagem dos sais pelas águas das chuvas, como ocorre naturalmente em áreas cultivadas a céu aberto. Nessas condições a recuperação desses solos é um processo demorado e bastante criterioso, sendo necessária a aplicação de grandes quantidades de água tanto quanto, também, o manejo adequado para cada tipo de solo (Duarte et al., 2007).

Portanto, a adição de fertilizantes via irrigação, sobretudo em cultivo protegido, pode contribuir para o aumento dos níveis de salinidade do solo, muitas vezes ultrapassando os limites de tolerância das culturas reduzindo o crescimento e o rendimento ao longo dos sucessivos cultivos.

O manejo da fertirrigação é realizado ministrando-se, na maioria das vezes, quantidades pre-estabelecidas de fertilizantes, parceladas com base na curva de absorção da cultura, não existindo, na maioria dos casos, monitoramento da condutividade elétrica da solução do solo ou do estado nutricional da planta. Neste aspecto seria relevante racionalizar o manejo da fertirrigação por meio da quantificação do teor de sais no solo (condutividade elétrica) e dos íons específicos da solução do solo, principalmente o nitrato e o potássio (Dias et al., 2007).

$\mathrm{O}$ aumento da salinidade no solo por excesso de fertilizantes, além de alterar o potencial osmótico do meio provoca, entretanto, desequilíbrios nutricionais e mesmo o solo úmido e com nutrientes, esses não são absorvidos pelas plantas, seja por desequilíbrio nutricional ou por efeito osmótico.

Dada à relevância da temática, torna-se de fundamental importância a determinação da tolerância das culturas ao excesso de sais fertilizantes uma vez que a maioria das informações existentes na literatura especializada é referente à tolerância das culturas à salinidade provocada pelo excesso de sais na água de irrigação (Eloi et al., 2007).

Objetivou-se com este trabalho avaliar o efeito do excesso de fertilizantes aplicados via irrigação em solo com diferentes níveis iniciais de salinidade advindos de cultivo anterior enfatizando, assim, o objetivo em estudar o excesso de sais provenientes de cultivos sucessivos sobre as variáveis produtivas do tomateiro.

\section{Material e Métodos}

$\mathrm{O}$ experimento foi conduzido em área experimental da Escola Superior de Agricultura Luiz de Queiroz (ESALQ/USP) no período de maio a setembro de 2010 em estufa plástica no Departamento de Engenharia de Biossistemas, no município de Piracicaba-SP, situado nas coordenadas geográficas de $22^{\circ}$ $42^{\prime}$ 'de latitude sul e $47^{\circ} 38^{\prime}$ ' de longitude oeste, a uma altitude de $540 \mathrm{~m}$.

O solo utilizado na pesquisa foi objeto de estudos em cultivos anteriores nos quais se tinha, como fonte de variação, o nível de condutividade elétrica (CE) da solução do solo ocasionada pela adição de fertilizantes em ambiente protegido, sendo o mesmo classificado como Litossolo, textura francoargilosa (Tabela 1).

A determinação da condutividade elétrica do extrato de saturação $\left(\mathrm{CE}_{\mathrm{es}}\right)$ seguiu metodologia proposta por Richards (1954) cuja caracterização química se encontra na Tabela 2. Para tanto, os valores foram organizados visando à distribuição da variação de salinidade do solo resultando nos níveis iniciais antes da implantação da cultura $(1,62 ; 2,40 ; 2,98 ; 3,48 ; 4,63$ e $5,62 \mathrm{dS} \mathrm{m}^{-1}$ ) provenientes do resíduo de sais do cultivo anterior de tomate.

Tabela 1. Caracterização físico-hídrica do solo utilizado no experimento

\begin{tabular}{|c|c|c|c|c|c|c|c|c|c|}
\hline \multicolumn{2}{|c|}{ Densidade } & \multicolumn{3}{|c|}{ Granulometria } & \multicolumn{2}{|c|}{ Umidade base peso } & \multicolumn{3}{|c|}{ Porosidade } \\
\hline Global & Partículas & Areia & Silte & Argila & $\mathrm{CC}^{*}$ & Residual & Micro & Macro & Total \\
\hline 1,19 & 2,91 & 440 & 170 & 390 & 28,27 & 6,1 & 33,64 & 25,47 & 59,11 \\
\hline
\end{tabular}

*Capacidade de contêiner 
Tabela 2. Caracterização química do solo utilizado no experimento

\begin{tabular}{|c|c|c|c|c|c|c|c|c|c|c|c|}
\hline CEes & pH & $N$ & M.0 & $\mathbf{P}$ & K & $\mathrm{Ca}$ & $\mathrm{Mg}$ & $\mathrm{H}+\mathrm{Al}$ & SB & CTC & V \\
\hline $\mathrm{dS} \mathrm{m}^{-1}$ & ${ }^{*} \mathrm{CaCl}_{2}$ & $\mathrm{mg} \mathrm{kg}^{-1}$ & $g \mathrm{dm}^{-3}$ & $\mathrm{mg} \mathrm{dm}^{-3}$ & \multicolumn{6}{|c|}{$\mathrm{mmol}_{\mathrm{c}} \mathrm{dm}^{-3}$} & $\%$ \\
\hline 1,62 & 5,1 & 1178 & 17 & 56 & 8,0 & 20 & 4 & 25 & 32,0 & 56,9 & 56 \\
\hline 2,40 & 4,8 & 1088 & 17 & 121 & 14,5 & 27 & 5 & 31 & 46,5 & 77,3 & 60 \\
\hline 2,98 & 4,4 & 1091 & 18 & 370 & 15,5 & 27 & 5 & 42 & 47,5 & 89,7 & 53 \\
\hline 3,48 & 4,4 & 1210 & 18 & 390 & 15,5 & 29 & 5 & 42 & 49,5 & 91,7 & 54 \\
\hline 4,63 & 4,5 & 1140 & 18 & 420 & 15,0 & 40 & 7 & 47 & 62,0 & 108,9 & 57 \\
\hline 5,82 & 4,8 & 1532 & 17 & 670 & 24,0 & 37 & 5 & 34 & 66,0 & 100,2 & 66 \\
\hline
\end{tabular}

${ }^{*} 0,01 \mathrm{mmolc} \mathrm{L}^{-1} \mathrm{CaCl}_{2}$ (acidez ativa)

Os tratamentos foram compostos pela combinação de dois fatores: seis níveis de salinidade do solo - $\mathrm{CE}_{\mathrm{es}}$ $\left(\mathrm{S}_{1}=1,62 ; \mathrm{S}_{2}=2,40 ; \mathrm{S}_{3}=2,98 ; \mathrm{S}_{4}=3,48 ; \mathrm{S}_{5}=4,63\right.$ es $\left.\mathrm{S}_{6}=5,82 \mathrm{dS} \mathrm{m}^{-1}\right)$ e dois manejos de fertirrigação $\left(\mathrm{M}_{1}\right.$ - Adubos aplicados em fertirrigação obedecendo à curva de absorção de nutrientes da cultura e $\mathrm{M}_{2}$ - Sem a aplicação de fertilizantes).

$\mathrm{O}$ delineamento estatístico adotado foi em blocos inteiramente casualizados, com quatro repetições, de modo que os fatores estudados foram arranjados em esquema fatorial $6 \mathrm{x}$ 2. Os 12 tratamentos propostos foram dispostos em 48 parcelas, ou seja, 48 vasos de $22,5 \mathrm{~L}$ espaçados $0,5 \mathrm{~m}$ entre plantas e $1,5 \mathrm{~m}$ entre linhas, tendo 2 vasos no início e no final de cada linha com função de bordadura. Cada unidade experimental foi composta por um vaso com orifícios na parte inferior, contendo uma camada de $1 \mathrm{~cm}$ de brita $\mathrm{n}^{\circ} 1$, recoberta com manta geotêxtil para facilitar a drenagem; os vasos foram completados com cerca de $20 \mathrm{~kg}$ de solo.

A cultivar de tomate utilizada foi a Débora Plus, do grupo Santa Cruz, uma das mais cultivadas em ambiente protegido com o propósito de investigar os problemas de salinidade causados por aplicação excessiva de fertilizantes no cultivo de tomate em ambiente protegido.

As mudas foram produzidas em bandejas de polietileno expandidas de 128 células, preenchidas com substrato comercial. $\mathrm{O}$ transplantio foi realizado utilizando-se uma muda por vaso, quando apresentava de quatro a cinco folhas definitivas, o que ocorreu por volta dos 25 dias após a semeadura. No interior da estufa foram instaladas estacas de concreto, às quais foram fixados arames número 14 na altura de $2,0 \mathrm{~m}$, procedimento este que veio a auxiliar o tutoramento vertical das plantas.

O sistema de irrigação empreendido foi o de gotejamento empregando-se emissores (on-line) do tipo autocompensante com vazão nominal de $3,0 \mathrm{~L} \mathrm{~h}^{-1}$ acoplados às linhas de irrigação (tubos de polietileno $16 \mathrm{~mm}$ ), com registros instalados no início de cada linha os quais permitiam aplicar volume diferenciado de água por tratamento, condição esta que se perfaz indispensável para o controle dos manejos de irrigação e fertirrigação, posto que evita possíveis contaminações salinas.

Avaliou-se o sistema de irrigação sob condições de 1,5 $\mathrm{kgf} \mathrm{cm}{ }^{-2}$ de pressão de operação, tendo apresentado coeficiente de uniformidade de $97,3 \%$. O manejo da irrigação foi baseado no monitoramento do potencial mátrico da água no solo obtido em tensiômetros instalados a $0,15 \mathrm{~m}$ de profundidade, e da curva característica de retenção de água no solo. A aplicação da irrigação foi realizada de acordo com a recomendação de Alvarenga (2004) sempre que a tensão se encontrava entre 10 a $15 \mathrm{kPa}$. A quantidade de água aplicada era suficiente para elevar a umidade à capacidade de campo sendo calculada mediante as médias das leituras tensiométricas, para cada tratamento.
A aplicação dos fertilizantes foi realizada juntamente com a água de irrigação, de modo que houve tratamentos diferenciados em função dos manejos de fertirrigação, $\mathrm{M}_{1}$ e $\mathrm{M}_{2}$. O manejo $M_{1}$ foi baseado na marcha de absorção da cultura proposta por Alvarenga (2004) em seu estudo sobre a produção de tomate em condições de campo, casa de vegetação e hidroponia, obedecendo aos seguintes valores para a adubação de mil plantas via fertirrigação: $\mathrm{N}=35 \mathrm{~kg} ; \mathrm{P}=14 \mathrm{~kg} ; \mathrm{K}=75 \mathrm{~kg}$ e $\mathrm{Ca}=10 \mathrm{~kg}$.

Para o tratamento referente ao manejo $M_{1}$ realizou-se a fertirrigação semanalmente de forma que as quantidades de fertilizantes aplicadas em todo o ciclo foram de 29,07; 31,14; 177,$23 ; 52,83 ; 22,22 \mathrm{~g}_{\text {planta }}{ }^{-1}$ de nitrato de amônio $\left(\mathrm{NH}_{4} \mathrm{NO}_{3}\right)$, fosfato monopotássico $\left(\mathrm{KH}_{2} \mathrm{PO}_{4}\right)$, nitrato de potássio $\left(\mathrm{KNO}_{3}\right)$, nitrato de cálcio $\left(\mathrm{Ca}\left(\mathrm{NO}_{3}\right)_{2}\right)$ e sulfato de magnésio $\left(\mathrm{MgSO}_{4}\right)$ respectivamente. Por outro lado, para o manejo $\mathrm{M}_{2}$ não se aplicou nenhum tipo de fertilizante durante todo o ciclo da cultura, ou seja, prevaleceram somente os níveis iniciais de fertilizantes no solo (Tabela 2).

As variáveis analisadas foram: número de frutos por planta; produção de fitomassa fresca medida no final do ciclo para frutos e produção de fitomassa seca medida no final do ciclo de haste, fruto, raiz, folhas, frutos e total incluindo o refugo $\left(\right.$ g planta $\left.^{-1}\right)$; estas foram acondicionadas em sacos de papel e levadas à estufa com circulação forçada de ar, na temperatura de $65 \pm 1{ }^{\circ} \mathrm{C}$, até atingir uma fitomassa constante obtida em balança de precisão de $0,01 \mathrm{~g}$.

Para obtenção da fitomassa seca da raiz peneirou-se todo o solo contido nos vasos e, logo em seguida, as raízes foram lavadas de maneira que todo o substrato fosse removido retirando-se o excesso de água com auxílio de papel toalha, sendo as raízes submetidas ao mesmo processo que as demais fitomassas. Avaliou-se, também, no final do ciclo, a área foliar $\left(\mathrm{cm}^{2}\right)$ por meio de um integrador eletrônico de área foliar, modelo LI-3100.

As variáveis foram analisadas estatisticamente pelo teste F desdobrando-se as análises sempre que a interação fosse significativa. Os fatores quantitativos relativos aos níveis de salinidade do solo, foram analisados estatisticamente por meio de regressão polinomial (linear e quadrática) com auxílio do programa computacional Sisvar (Ferreira, 2000).

\section{Resultados E Discussão}

O resumo da análise de variância para as variáveis fitomassas secas de folhas (FSF); de haste (FSH); de raiz (FSR) e fitomassa fresca de frutos (FFFR) do tomateiro, em função dos níveis de salinidade e manejos da fertirrigação, encontra-se na Tabela 3. 
Tabela 3. Resumo da análise da variância e médias das fitomassas secas de folhas (FSF), de haste (FSH), de raiz (FSR) e fitomassa fresca de fruto (FFFR), para a cultura do tomate em função dos níveis de salinidade e dos manejos de fertirrigação

\begin{tabular}{|c|c|c|c|c|c|}
\hline $\begin{array}{l}\text { Fonte de } \\
\text { variação }\end{array}$ & GL & FSF & FSH & FSR & FFFR \\
\hline Salinidade (S) & 5 & $2,78^{*}$ & $4,70^{\star *}$ & $5,79^{* *}$ & $6,05^{\star *}$ \\
\hline Reg. Linear & 1 & $3,04^{\text {ns }}$ & $3,72^{\mathrm{ns}}$ & $2,55^{\mathrm{ns}}$ & $22,36^{\star *}$ \\
\hline Reg. Quadrática & 1 & $4,45^{\star}$ & $10,10^{\star *}$ & $20,06^{* *}$ & $0,88^{\text {ns }}$ \\
\hline Manejo (M) & 1 & $235,91^{\star \star}$ & $70,17^{\star \star}$ & $50,28^{\star \star}$ & $12,85^{\star \star}$ \\
\hline SXM & 5 & $2,85^{\star \star}$ & $2,07^{\text {ns }}$ & $1,42^{\text {ns }}$ & $6,11^{\star \star}$ \\
\hline Bloco & 3 & 4,94 & 1,22 & 1,51 & 3,94 \\
\hline Média geral & - & 257,14 & 122,27 & 26,26 & 955,17 \\
\hline CV(\%) & - & 12,01 & 10,11 & 14,56 & 19,64 \\
\hline Manejo (M) & \multicolumn{5}{|c|}{ Valores médios ${ }^{\#}$ - g } \\
\hline M1 & - & $326,82 a$ & $137,22 \mathrm{a}$ & $30,44 a$ & $1052,26 a$ \\
\hline M2 & - & $187,45 b$ & $107,32 \mathrm{~b}$ & $22,07 \mathrm{~b}$ & $858,07 \mathrm{~b}$ \\
\hline
\end{tabular}

\# Médias seguidas de mesma letra na coluna não diferem entre si em nível de 0,05 de probabilidade, pelo teste de Tukey; ns - Não significativo em nível de 0,05 de probabilidade, pelo teste F; *; * Significativo em nível de 0,05 e 0,01 de probabilidade, respectivamente, pelo teste $\mathrm{F}$

Observou-se efeito significativo da salinidade inicial do solo sobre a variável fitomassa seca de folha (FSF) $(\mathrm{p}<0,05)$ e sobre as variáveis fitomassa seca de haste (FSH), de raiz (FSR) e fitomassa fresca de frutos (FFFR) a nível de 0,01 de probabilidade. Com efeito quadrático significativo a ( $p<0,05$ e p $<0,01$ ) para as variáveis FSF, FSH e FSR, respectivamente; já na variável FFFR observou-se efeito linear $(\mathrm{p}<0,01)$. $\mathrm{O}$ fator manejo foi significativo em nível de $(p<0,01)$ para as quatro variáveis estudadas. Verificou-se efeito significativo para a interação entre salinidade e manejo (S X M) a nível de (p < 0,01) para as variáveis FSF e FFFR (Tabela 3).
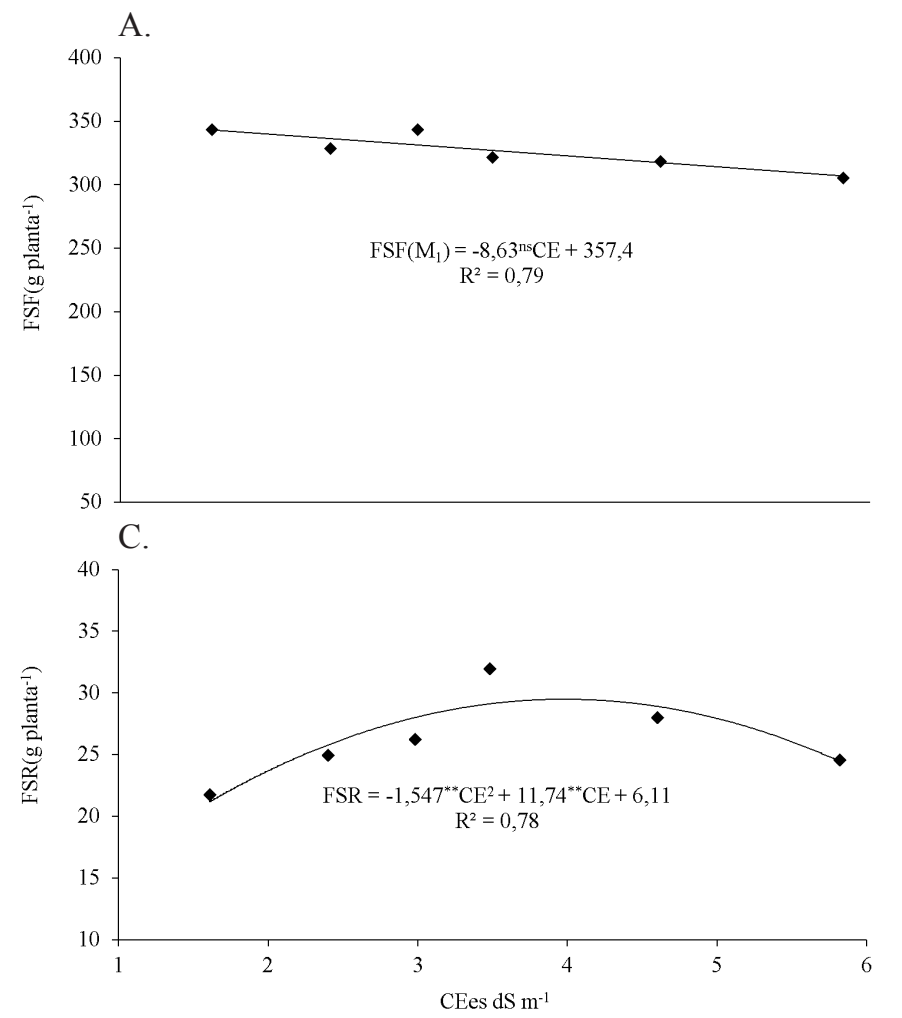

Em relação ao estudo isolado da variável manejo da fertirrigação observa-se, na Tabela 3, que as variáveis fitomassa seca de haste e raiz no manejo $M_{1}$ diferiram significativamente do manejo $M_{2}$, sendo as médias observadas no manejo $M_{1}$, superiores às observadas no $\mathrm{M}_{2}$.

Houve efeito da interação entre salinidade inicial do solo e manejo da fertirrigação para a variável fitomassa seca de frutos (Figura 1A), para o manejo $\mathrm{M}_{1}$ a taxa de decréscimos relativos na produção ou redução por incremento unitário de condutividade elétrica do extrato de saturação do solo, foi de $2,65 \%$. Em contrapartida, no manejo $\mathrm{M}_{2}$ ocorreu, inicialmente, um aumento na FSF, com ponto de máxima produção em 3,5 dS $\mathrm{m}^{-1}$, e posterior redução sendo a diferença entre $\mathrm{S}_{1}$ e $\mathrm{S}_{6}$ de $4,8 \%$ representada pela equação de regressão $\mathrm{FSF}\left(\mathrm{M}_{2}\right)=-5,47^{* *} \mathrm{CE}+$ $38,92^{* *} \mathrm{CE}+120,4$ com coeficiente de determinação $\mathrm{R}^{2}=0,52$, corroborando com Silva (2010) em trabalho sobre o manejo da fertirrigação em ambiente protegido visando ao controle da salinidade do solo para a cultura da berinjela.

Medeiros et al. (2007) também observaram, estudando o crescimento do meloeiro cultivado sob diferentes níveis de salinidade, com e sem cobertura de solo e com níveis elevados de salinidade da água, uma redução significativa da fitomassa da parte aérea das plantas. A redução na quantidade de água disponível e a consequente diminuição na quantidade de água absorvida provocam, combinadas com os distúrbios nutricionais provocados pelo meio salinos, reduções consideráveis no crescimento das plantas, as quais apresentam, como resultado, folhas menores porém mais espessas (Bresler et al., 1982).

Para a variável FSH a equação que melhor se ajustou para o fator salinidade isolado foi a quadrática (Figura 1B) sendo

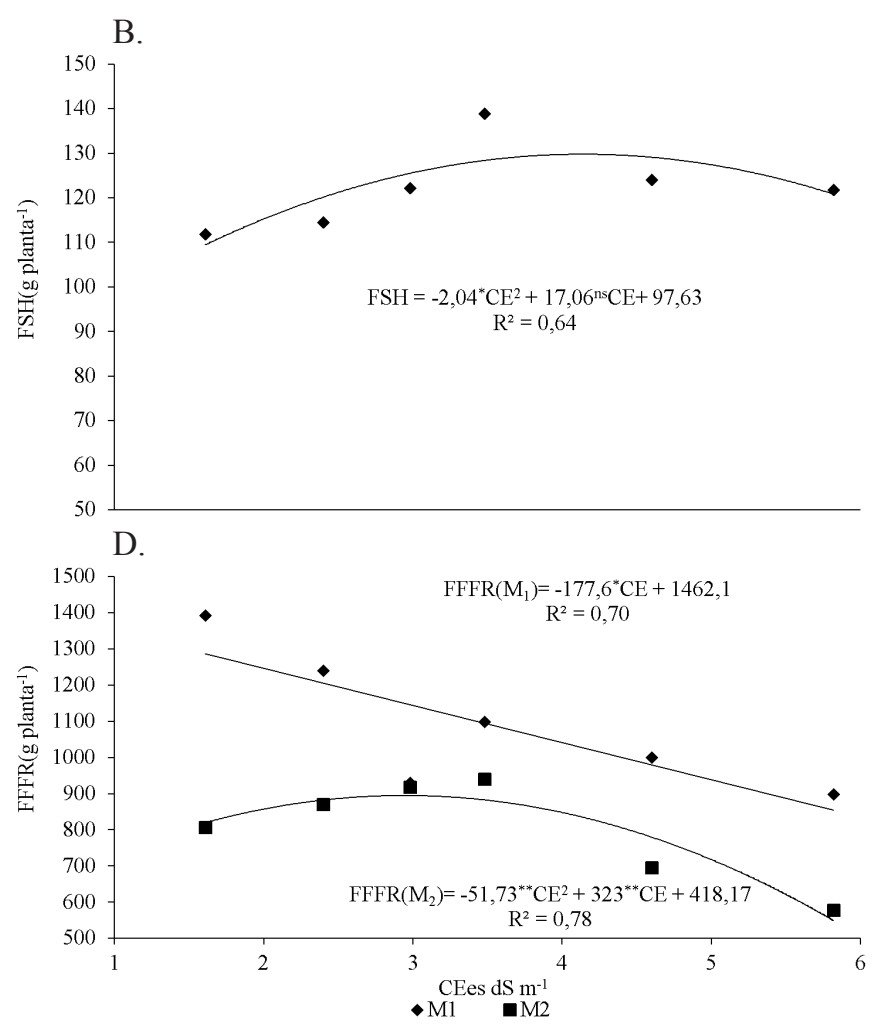

Figura 1. Diagrama de dispersão com desdobramento da salinidade dentro de cada manejo para a Fitomassa seca de folha - FSF (A), análise isolada da salinidade para fitomassa seca de haste - FSH e raiz - FSR (B e C) e desdobramento dos fatores para a fitomassa fresca de frutos - FFFR (D) 
o ponto de máximo $4,18 \mathrm{dS} \mathrm{m}^{-1}$ a partir do qual o rendimento começa a declinar com uma diferença de $6,34 \%$ entre o menor $\left(\mathrm{S}_{1}\right)$ e o maior nível de salinidade inicial do solo $\left(\mathrm{S}_{6}\right)$.

De acordo com a equação de regressão (Figura 1C) a fitomassa seca de raiz atingiu seu ponto de máximo em 3,99 $\mathrm{dS} \mathrm{m} \mathrm{m}^{-1}$ e diferença entre $\mathrm{S}_{6}$ comparada a $\mathrm{S}_{1}$ de 5,28\%. Freire et al. (2010) e Campos et al. (2007) relataram, em seus estudos com tomate, que não houve efeito significativo da salinidade em relação à massa seca de raízes de plantas avaliadas.

Segundo Soares et al. (2011) em condições de elevada salinidade a fitomassa seca de haste, raízes e folhas de plantas do tomateiro são reduzidas assim como o consumo de água. Para tanto, a fitomassa do sistema radicular é fundamental na avaliação de plantas pois um sistema radicular bem desenvolvido pode proporcionar melhores condições de suprimento da demanda de água e nutrientes para as plantas principalmente nas primeiras semanas quando as condições adversas podem comprometer sua sobrevivência.

Em relação à variável fitomassa fresca de frutos, o modelo matemático que melhor se ajustou para o manejo $M_{1}$ foi $o$ linear (Figura 1D), com decréscimos relativos de produção, de $\mathrm{S}_{2}$ comparando a $\mathrm{S}_{1}$ de 7,21\%; entre $\mathrm{S}_{3}$ e $\mathrm{S}_{1}$ de $12,53 \%$; entre $\mathrm{S}_{4}$ e $\mathrm{S}_{1}$ de $17,19 \%$; entre $\mathrm{S}_{5}$ e $\mathrm{S}_{1}$ de $27,83 \%$ e entre $\mathrm{S}_{6}$ e $\mathrm{S}_{1}$ de $38,82 \%$. Verifica-se, ainda, de acordo com o modelo matemático, que a taxa de decréscimo relativo ou redução por incremento unitário de condutividade elétrica do extrato de saturação do solo foi de 9,24\%.

A interação dos fatores teve comportamento quadrático sobre a fitomassa fresca de frutos no manejo $\mathrm{M}_{2}$ (Figura 1D), com limiar de $3,12 \mathrm{dS} \mathrm{m}^{-1}$, sendo a diferença observada entre $\mathrm{S}_{1}$ e $\mathrm{S}_{6}$ de 32,23\%. A máxima produção de FFFR para manejo $\mathrm{M}_{2}$ em $\mathrm{S}_{2}$ representou $64 \%$ da máxima produção obtida em $\mathrm{M}_{1}$.

Com base nesses resultados observa-se, para o $M_{1}$, que as variáveis fitomassa seca de folha e fitomassa fresca de fruto do tomateiro foram influenciadas negativamente pelo aumento da $\mathrm{CE}_{\mathrm{es}}$ do solo uma vez que essas variáveis foram mais sensíveis ao maior nível de salinidade $\left(\mathrm{S}_{6}\right)$ quando comparadas ao menor nível $\left(\mathrm{S}_{1}\right)$.

Tal resultado se assemelha ao encontrado por Silva et al. (2013) em seu estudo sobre o manejo da fertirrigação em berinjela, o qual visou ao controle da salinidade do solo em ambiente protegido e concordando com resultados encontrados por Botrini et al. (2000) que, trabalhando com solução nutritiva altamente salina, concentração de $\mathrm{NaCl}$ equivalente a 8770 mg $\mathrm{L}^{-1}$ e quantidades crescentes de $\mathrm{K}$, observaram que a produção da massa seca da parte aérea e do sistema radicular do tomateiro foi reduzida; contudo e segundo os autores, este resultado foi basicamente influenciado pelo aumento dos fertilizantes aplicados.

O resumo da análise de variância para as variáveis, fitomassa seca de frutos (FSFR), número de frutos por planta (NFR), fitomassa seca total (FST) e área foliar (AF) do tomateiro, em função dos níveis de salinidade e dos manejos da fertirrigação encontra-se na Tabela 4. Houve efeito significativo da salinidade inicial do solo sobre as variáveis fitomassa seca de frutos (FSFR) e número de frutos (NFRP) $(\mathrm{p}<0,05)$, para fitomassa seca total $(\mathrm{p}<0,01)$ e para a área foliar não houve significância para o fator salinidade. O manejo da fertirrigação para todas as variáveis e a interação entre os fatores, foram significativos a 0,01 e 0,05 de probabilidade, respectivamente (Tabela 4).

Tabela 4. Resumo da análise da variância e médias de fitomassa seca de fruto (FSFR), número de frutos por planta (NFRP), fitomassa seca total (FST) e área foliar por planta (AF), para a cultura do tomate, em função dos níveis de salinidade e dos manejos de fertirrigação

\begin{tabular}{lccccc}
\hline \multicolumn{1}{c}{$\begin{array}{c}\text { Fonte de } \\
\text { variação }\end{array}$} & GL & FSFR & NFRP & FST & AF \\
Salinidade (S) & 5 & $3,59^{*}$ & $3,24^{\star}$ & $7,85^{\star *}$ & $2,23^{\text {ns }}$ \\
Reg. Linear & 1 & $6,61^{*}$ & $7,26^{*}$ & $2,85^{\text {ns }}$ & $3,90^{\text {ns }}$ \\
Reg. Quadrática & 1 & $4,20^{*}$ & $0,22^{\text {ns }}$ & $15,41^{\star *}$ & $4,21^{\star *}$ \\
Manejo (M) & 1 & $26,09^{* *}$ & $77,62^{* *}$ & $299,58^{* *}$ & $347,24^{* *}$ \\
S X M & 5 & $2,81^{*}$ & $1,97^{\star}$ & $6,23^{* *}$ & $3,07^{\star}$ \\
Bloco & 3 & 3,56 & 4,15 & 6,64 & 3,80 \\
\hline Média geral & - & 128,53 & 28,93 & 532,97 & 24087,44 \\
CV (\%) & - & 16,19 & 21,34 & 7,92 & 12,27 \\
\hline & & \multicolumn{5}{c}{ Valores Médios } \\
Manejo (M) & & $\mathrm{g}$ & $\mathrm{g}$ \\
M & - & $143,87 \mathrm{a}$ & $36,79 \mathrm{a}$ & $638,36 \mathrm{a}$ & $32034,70 \mathrm{a}$ \\
M2 & - & $113,19 \mathrm{~b}$ & $21,08 \mathrm{~b}$ & $427,57 \mathrm{~b}$ & $16140,18 \mathrm{~b}$ \\
\hline
\end{tabular}

\# Médias seguidas de mesma letra na coluna não diferem entre si em nível de 0,05 de probabilidade, pelo teste de Tukey; ns - Não significativo em nível de 0,05 de probabilidade, pelo teste $\mathrm{F} ;{ }^{*} ;{ }^{* *}$ Significativo em nível de 0,05 e 0,01 de probabilidade, respectivamente, pelo teste $\mathrm{F}$

O desdobramento da interação para os fatores estudados em relação à fitomassa seca de frutos manejo $\mathrm{M}_{1}$ (Figura $2 \mathrm{~A}$ ) evidenciou redução com o aumento da concentração salina da solução de saturação, sendo que a equação que melhor se ajustou foi a linear, com perda relativa para a produção, de $\mathrm{S}_{2}$ comparado a $\mathrm{S}_{1}$ de $2,22 \% ; \mathrm{S}_{3}$ e $\mathrm{S}_{1}$ de $5,63 \% ; \mathrm{S}_{4}$ e $\mathrm{S}_{1}$ de $7,97 \%$ $\mathrm{S}_{5}$ e $\mathrm{S}_{1}$ de $12,46 \%$; e $\mathrm{S}_{6}$ e $\mathrm{S}_{1}$ de $17,39 \%$. Constatou-se, ainda, de acordo com a equação de regressão para o manejo $M_{1}$, que a taxa de decréscimo por incremento unitário de salinidade provocada pela adição de sais fertilizantes foi de $4,14 \%$. A FSFR teve comportamento quadrático para o $\mathrm{M}_{2}$ com ponto de máximo em $3,31 \mathrm{dS} \mathrm{m}^{-1}$, sendo a perda relativa entre o nível menor e maior no manejo $\mathrm{M}_{2}$ de $17,07 \%$ (Figura 2A).

Eloi et al. (2007) encontraram, ao utilizar a mesma cultura em solo franco arenoso, valores de salinidade limiar entre 2,98 e 3,03 dS m $\mathrm{m}^{-1}$, com decréscimos relativos de produção que variaram entre 9,38 e 10,95\%, para cada aumento unitário de salinidade do solo provocada pela aplicação de sais fertilizantes.

Cosme et al. (2011) obtiveram, em estudo sobre a produção de tomate hidropônico em que foi utilizado rejeito da dessalinização na solução nutritiva aplicados em diferentes épocas, resultados similares aos do presente trabalho; todavia, a redução ocorreu a partir do nível médio de salinidade da solução nutritiva $\left(8,7 \mathrm{dS} \mathrm{m}^{-1}\right)$, chegando a diminuir em $21,5 \%$ a fitomassa seca, quando comparada com a aplicação do nível de salinidade mais baixo $\left(2,1 \mathrm{dS} \mathrm{m}^{-1}\right)$ com o nível mais elevado $\left(10,1 \mathrm{dS} \mathrm{m}^{-1}\right)$.

De acordo com a equação de regressão para o número de frutos por planta (NFRP), resultante do desdobramento dos fatores para o $M_{1}$ (Figura $2 \mathrm{~B}$ ) evidenciou-se que quando se aumentava o nível de salinidade inicial do solo, as perdas relativas para a variável foram de $27,31 \%$; já para NFRP no $\mathrm{M}_{2}$ a equação de regressão que melhor se ajustou foi a quadrática $\operatorname{NFRP}\left(\mathrm{M}_{2}\right)=-0,81^{\mathrm{ns}} \mathrm{CE}^{2}+4,73 * \mathrm{CE}+14,98$ com coeficiente de determinação $\mathrm{R}^{2}=0,53$. 

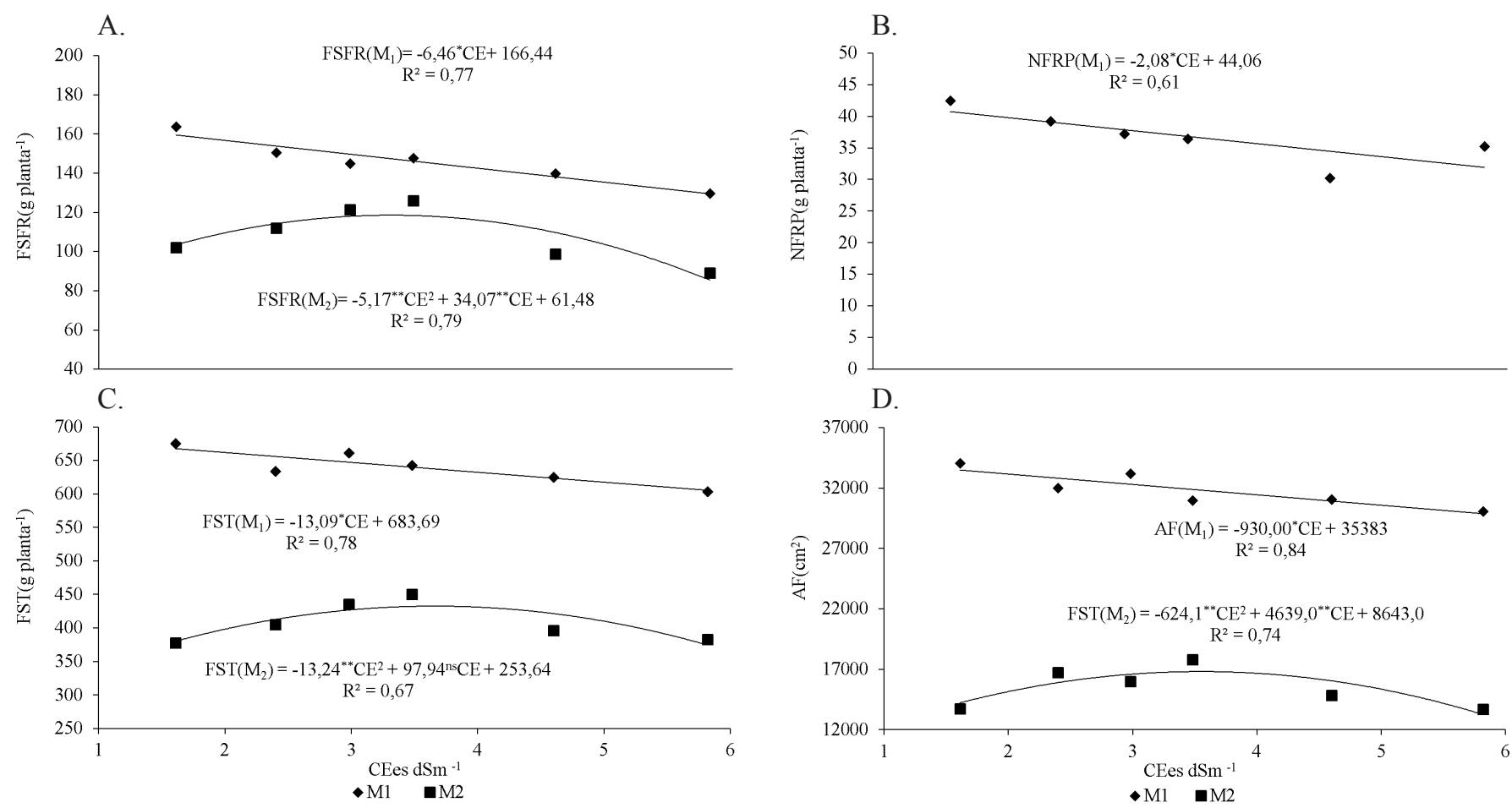

Figura 2. Diagramas de dispersão para interação entre os fatores, relativos à fitomassa seca de frutos FSFR (A), número de frutos por planta NFRP (B), fitomassa seca total FST (C) e área foliar AF (D) do tomateiro em ambiente protegido

Nos tratamentos que corresponderam aos maiores níveis de salinidade do solo os efeitos foram mais severos sobre o número de frutos por planta e fitomassa fresca de frutos quando comparados com os das demais variáveis estudadas sugerindo que nos tratamentos com maiores salinidades houve maior abortamento das flores femininas e consequentemente redução na produção de frutos comerciais. Concordando com os estudos de Medeiros et al. (2012) e Eloi et al.(2007) esses autores afirmam que o tomateiro, quando cultivado sob salinidade elevada, reduz sua produtividade, resultado este do menor número de frutos produzidos por planta.

De acordo com Cosme et al. (2011) a produção de frutos foi a variável mais afetada pela salinidade da solução nutritiva haja vista que a redução atingiu 33,0\% entre o nível de maior salinidade $\left(10,1 \mathrm{dS} \mathrm{m}^{-1}\right)$ com o menor nível $\left(7,1 \mathrm{dS} \mathrm{m}^{-1}\right)$ e uma diferença de $51,4 \%$ entre a média dos tratamentos e a testemunha evidenciando que a produção dos frutos do tomateiro é reduzida com a exposição das plantas à salinidade, o que ocasiona diminuição da produtividade do tomateiro.

Em relação à variável fitomassa seca total (FST) verificouse efeito linear para o manejo $\mathrm{M}_{1}$ (Figura 2C) de modo que os decréscimos relativos de 1,$54 ; 2,68 ; 3,66 ; 5,93 ;$ e $8,27 \%$, respectivamente, para $\mathrm{S}_{2} ; \mathrm{S}_{3} ; \mathrm{S}_{4} ; \mathrm{S}_{5}$ e $\mathrm{S}_{6}$ comparados a $\mathrm{S}_{1}$.

$\mathrm{O}$ decréscimo por incremento unitário para esta variável foi de 1,97\%. Quanto ao manejo $\mathrm{M}_{2}$, o ajuste foi quadrático (Figura 2C), com salinidade limiar para a variável de 3,69 $\mathrm{dS} \mathrm{m}^{-1}$ e a diferença entre o maior e menor nível de salinidade do extrato de saturação foi de 1,7\%. Blanco et al. (2008) observaram, em estudo sobre a tolerância do tomateiro à salinidade em Piracicaba-SP, um aumento da fitomassa seca com incremento dos níveis de salinidade e posteriormente redução corroborando com os resultados observados no presente trabalho.
De acordo com os estudos de regressão, o modelo que melhor se ajustou à AF no manejo $M_{1}$ foi o linear (Figura 2D) com decréscimo de $\mathrm{S}_{2}$ comparado a $\mathrm{S}_{1}$ de 2,14; entre $\mathrm{S}_{3}$ e $\mathrm{S}_{1}$ de $3,74 \% ; S_{4}$ e $S_{1}$ de $5,12 \% ; S_{5}$ e $S_{1}$ de $8,29 \%$ e entre $S_{6}$ e $S_{1}$ de $11,56 \%$, sendo o decréscimo por incremento unitário de salinidade $2,75 \%$. Contudo, no $\mathrm{M}_{2}$ a área foliar se ajustou a um modelo quadrático (Figura 2D) com limiar de 3,54 $\mathrm{dS} \mathrm{m}^{-1}$ e a diferença entre o maior e menor nível de salinidade inicial do solo, $6,68 \%$.

O decréscimo linear de algumas variáveis pode ter ocorrido em função do aumento da concentração de sais na zona radicular, o que causa redução na absorção de água e nutrientes pela planta, fazendo com que esta altere seu metabolismo. Resultados semelhantes foram encontrados por Oliveira et al. (2007) e Najla et al. (2007) analisando as variáveis produtivas do tomateiro submetido a diferentes níveis de sais.

Para Blanco \& Folegatti (2002) e Silva et al. (2013) o aumento da concentração salina da solução do solo provocou redução na fitomassa seca total e na área foliar, com o valor máximo para salinidade de aproximadamente $4,5 \mathrm{dS} \mathrm{m}^{-1} \mathrm{em}$ trabalhos com pepino e berinjela, respectivamente, quando cultivados com excesso de sais fertilizantes.

Contudo, o decréscimo na produção de massa seca, produtividade total e comercial em tomate cultivado em solo submetido ao aumento da salinidade tem sido reportado por diversos autores (Campos et al., 2006; Magan et al., 2008; Albusaidi et al., 2009).

Assim sendo, para o tratamento em que se aplicou a curva de absorção da cultura as variáveis tiveram redução na produção a partir do primeiro nível de salinidade; em contrapartida, para os tratamentos em que não se aplicaram fertilizantes as variáveis analisadas aumentaram no início a produção, de modo a se obter um ponto de máximo em média na CEes de 3,69 
$\mathrm{dS} \mathrm{m} \mathrm{m}^{-1}$. Concordando com o trabalho de Eloi et al. (2007) que em seus estudos utilizando a mesma cultivar do presente trabalho afirmam não haver prejuízos significativos sobre a produção total do tomateiro, quando a condutividade elétrica do extrato de saturação proporcionada pela adição de fertilizantes, é inferior a 3,03 dS m${ }^{-1}$, e diferindo dos resultados obtidos por Medeiros et al. (2012) que observaram uma salinidade limiar de $1,278 \mathrm{dS} \mathrm{m}^{-1}$ com decréscimo de $15,96 \%$ na produtividade a cada incremento unitário na salinidade limiar.

\section{ConclusõES}

1. Os níveis de salinidade do solo provocados por excesso de fertilizantes em cultivos anteriores e associados a novas aplicações de fertilizantes conforme curva de absorção dos nutrientes $\left(\mathrm{M}_{1}\right)$ reduzem significativamente os componentes de produção do tomateiro.

2. As variáveis fitomassa fresca de frutos e o número de frutos foram afetados estatisticamente tanto pelo tipo de manejo de fertirrigação adotado quanto pelos níveis de salinidade do solo com reduções de 38,82 e 27,31\% para o manejo $M_{1}$.

3. A interação entre os fatores estudados (Salinidade Inicial $x$ Manejo da Fertirrigação) foi significativa para os componentes de produção estudados exceto para FSH e FSR.

4. O manejo $M_{1}$ foi superior para todos os componentes de produção estudados quando comparado ao manejo sem a aplicação dos fertilizantes $\left(\mathrm{M}_{2}\right)$.

5. A cultivar de tomate Débora Plus apresentou maior tolerância à salinidade que a encontrada na literatura $(2,5$ $\mathrm{dS} \mathrm{m}^{-1}$ ).

\section{Literatura Citada}

Al-busaidI, A.; Al-rawahY, S.; Ahmed, M. Response of different tomato cultivars to diluted seawater salinity. Asian Journal of Crop Science, v.1, p.77-86, 2009.

Alvarenga, M. A. R. Tomate: Produção em campo, em casade-vegetação e em hidroponia. Lavras: UFLA, 2004. 400p.

Ayers, R. S.; Westcot, D. W. A qualidade da água na agricultura. Campina Grande: UFPB, 1991. 218p.

Bernardo, S.; Soares, A. A.; Mantovani, E. C. Manual de Irrigação. 08. ed. Viçosa: UFV, 2006. 625p.

Blanco, F. F.; Folegatti, M. V. Padrão de distribuição de área foliar do pepino cultivado em ambiente protegido. Horticultura Brasileira, v.18, p.254-256, 2002.

Blanco, F. F.; Folegatti, M. V.; Henriques Neto, D. Doses de $\mathrm{N}$ e K no tomateiro sob estresse salino: I. Concentração de nutrientes no solo e na planta Revista Brasileira de Engenharia Agrícola e Ambiental, v.12, p.26-33, 2008.

Botrini, L.; Paola, M. L.; Graifenberg, A. Potassium affects sodium content in tomato plants grown in hydroponic cultivation under saline-sodic stress. HortScience, v.35, p.1220-1222, 2000.

Bresler, E.; McNeal, B. L.; Carter, D. L. Saline and sodic soils: Principles, dynamics and modeling. New York: Springer, 1982. 236p.

Campos, C. A. B.; Fernandes, P. D.; Gheyi, H. R.; Blanco, F. F. Tomato growth and dry matter partitioning as a function of the irrigation water quality. Revista Ciência Agronômica, v.38, p.239-246, 2007.
Campos, C. A. B.; Fernandes, P. D.; Gheyi, H. R.; Blanco, F. F.; Gonçalves, C. B.; Campos, S. A. F. Yield and fruit quality of industrial tomato under saline irrigation. Scientia Agricola, v.63, p.146-152, 2006.

Carvalho, J. L.; Pagliuca, L. G.. Tomate: Um mercado que não pára de crescer globalmente. Revista Hortifruti Brasil, ano 6, n.58, p.6-14. 2007.

Cosme, C. R.; Dias, N. da S.; Oliveira, A. M.; Oliveira, E. M. M.; Sousa Neto, O. N. Produção de tomate hidropônico utilizando rejeito da dessalinização na solução nutritiva aplicados em diferentes épocas. Revista Brasileira de Engenharia Agrícola e Ambiental, v.15, p.499-504, 2011.

Dias, N. da S.; Duarte, S. N.; Teles Filho, J. F.; Yoshinaga, R. T. Salinização do solo por aplicação de fertilizantes em ambiente protegido. Irriga, v.12, p.135-143, 2007.

Duarte, S. N.; Dias, N. da S.; Teles Filho, J. F. Recuperação de um solo salinizado devido a excesso de fertilizantes em ambiente protegido. Irriga, v.12, p.422-428, 2007.

Eloi, W. M.; Duarte, S. N.; Soares, T. M. Níveis de salinidade e manejo da fertirrigação sobre características do tomateiro cultivado em ambiente protegido. Revista Brasileira de Ciências Agrárias, v.2, p.83-89, 2007.

Ferreira, D. F. Análise estatística por meio do SISVAR (Sistema para Análise de Variância) para Windows versão 4.0. In: Reunião Anual da Região Brasileira da Sociedade Internacional de Biometria. Anais... São Carlos: UFSCar, v.45, 2000. p.255-258.

Filgueira, F. A. R. Manual de olericultura. Agrotecnologia moderna na produção e comercialização de hortaliças. Viçosa: UFV, 2.ed. 2008. 421p.

Freire, A. L.; Saraiva V. P.; J Miranda, J. R. P.; Bruno, G. B. Crescimento, acúmulo de íons e produção de tomateiro irrigado com água salina. Revista Ciências Agrárias, v.31, p.1133-1144, 2010.

Luz, J. M. Q.; Shinzato, A. V.; Silva, M. A. D. Comparação dos sistemas de produção de tomate convencional e orgânico em cultivo protegido. Bioscience Journal, v.23, p.7-15, 2007.

Maas, E. V. Crop salt tolerance. In: Tanji, K. K. (ed.) Agricultural salinity assessment and management manual. New York: ASCE, 1990. p.262-304.

Magan, J. J.; Gallardob, M.; Thompsonb, R. B.; Lorenzoc, P. Effects of salinity on fruit yield and quality of tomato grown in soil-less cultire in greenhouses in Mediterranean climatic conditions. Agricultural Water Management, v.95, p.1041-1055, 2008.

Medeiros, J. F. de; Santos, S. C. L.; Câmara, M. J. T.; Negreiros, M. Z. Produção de melão Cantaloupe influenciado por coberturas do solo, agrotêxtil e lâminas de irrigação. Horticultura Brasileira, v.25, p.538-543, 2007.

Medeiros, P. R. F.; Duarte, S. N.; Uyeda, C. A.; Silva, E. F. F. Tolerância da cultura do tomate à salinidade do solo em ambiente protegido. Revista Brasileira de Engenharia Agrícola e Ambiental, v. 16, p.51-55, 2012.

Najla, S.; Vercambre, L.; Pagès, D.; Grasselly, H.; Gautier, M. G. Effect of salinity on tomato plant architecture. Acta Horticulturae, v.801, p.1183-1190, 2007.

Oliveira, C. B.; Cardoso, M. A. A.; Oliveira, J. C.; Oliveira, F. A.; Cavalcante, L. F. Características produtivas do tomateiro submetido a diferentes níveis de sais, na água de irrigação. Revista Brasileira de Engenharia Agrícola e Ambiental, v.11, p.11-16, 2007. 
Richards, L. A. Diagnosis and improvement of saline and alkali soils. Washington: United States Salinity Laboratory. 1954. 160p. Agriculture Handbook, 60

Silva, E. M. da. Manejo da fertirrigação em ambiente protegido visando o controle da salinidade do solo para a cultura da berinjela. Piracicaba: ESALQ/USP, 2010. 78p. Dissertação Mestrado

Silva, E. M.; Lima, C. J. G. S.; Duarte, S. N.; Barbosa, F. S.; Maschio, R. Níveis de salinidade e manejo da fertirrigação sobre características da berinjela cultivada em ambiente protegido. Revista Ciência Agronômica, v.44, p.150-158, 2013.
Silva, M. O.; Freire, M. B. G. S.; Mendes, A. M.; Freire, F. J.; Sousa, C. E. S.; Góes, G. B. Crescimento de meloeiro e acúmulo de nutrientes na planta sob irrigação com águas salinas. Revista Brasileira de Engenharia Agrícola e Ambiental, v.12, p.593-605, 2008.

Soares, L. A. A; Lima, G. S.; Brito, M. E. B.; Sá, F. V. S.; Araújo, T. T. Crescimento do tomateiro e qualidade física dos frutos sob estresse hídrico em ambiente protegido. Revista Verde de Agroecologia e Desenvolvimento Sustentável, v.6, p.203-212, 2011. 